\title{
EXERGETIC ANALYSIS OF A SOLAR PHOTOVOLTAIC TRACKING SYSTEM IN ERBIL, IRAQI
}

\author{
MAHDE AKram Molan, Dr. Idres AZZAT HAMAKhan ${ }^{*}$, and SARKAR JAWHAR M.ShareeF ${ }^{* *}$ \\ *Dept. of Mechanics, College of Engineering, University of Salahaddin, Kurdistan Region-Iraq \\ ** Dept. of Electrics, College of Engineering, University of Salahaddin, Kurdistan Region-Iraq
}

\begin{abstract}
This paper investigates exergy analysis of a solar photovoltaic system that is designed, constructed and tested in Mechanical engineering department, Salahaddin University-Erbil $36^{\circ} 14^{\prime \prime} \mathrm{N}, 4^{\circ} 01^{\prime} \mathrm{E}$.

Exergy analysis is used to estimate the exergy destruction losses during the PV module conversion process by using the second law of thermodynamics and to refine and predict the variations in solar photovoltaic behaviour. The electrical and operating considerations of a photovoltaic module include total solar irradiation, maximum generated power by the system, voltage, open-circuit voltage, current, short circuit current, cell temperature, and ambient temperature.

To find sun's position in the sky LDRs (light dependent resistors) are used as an input feedback and rotate the PV module to track the sun using motors and actuators. Quantity of four LDRs mounted on the solar tracking system frame used to find the light intension difference between all four directions north, south, east and west. The system is automatically controlled by PLC system and is able to rotate the photovoltaic module to follow altitude angle of the sun between 00 to 900 using a 24 inches $36 \mathrm{~V}$ DC actuator and a $12 \mathrm{~V}$ high torque DC motor is used to rotate the photovoltaic module toward east and west to follow the sun's azimuth angle for 360 degrees.

The results show that most of the solar irradiance value is dissipated and not entered to the PV module. However, this dissipation of energy results in decreasing the value of the energy and exergy input to the system. The increase in the value of the energy and exergy losses from the morning to about the noon time is because of increasing of the surface temperature of the solar module. From the output of this work, the authors suggested that the module should be reconstructed and redesigned which is suitable for the Kurdistan environment. The suitable one of the PV is to be designed in a way that the temperature rise within the module is not increased the standard level which is $25^{\circ} \mathrm{C}$, however the temperature rise is will reach about $50{ }^{\circ} \mathrm{C}$ in the summer. That is why the authors prefer to reconstruct the module.
\end{abstract}

KEYWORDS: Solar PV; Solar Tracking System; Electrical Energy; Energy Efficiency; Exergy Efficiency

\section{INTRODUCTION}

B ecause of the increasing anxiety and perception of environment in the world, power generation from renewable energy sources, mainly solar power has become important for the last years. Solar energy has an alternating character falling upon the earth and is depends on the year's season, weather, position the surface. Researchers have been working towards the improvement of efficiency, low cost materials and fabrication of solar cells using several methods.

Solar PV module converts sunlight directly into electrical energy. Direct current electricity is produced, which can be used or stored. Current PV modules have higher efficiency, lower cost, and high reliability than previous model. Many users take into account the value of PV systems for different applications.

The solar tracking system mechanism for the PV modules used to follow the sun in the sky from sun-rise to sun-sets by using solar detector like light dependent resistors LDR to find sun's position in the sky and rotate the PV module toward the sun using motors and actuators. The block diagram of the system is shown in figure 1 , in which all electrical, mechanical and control parts are shown. 


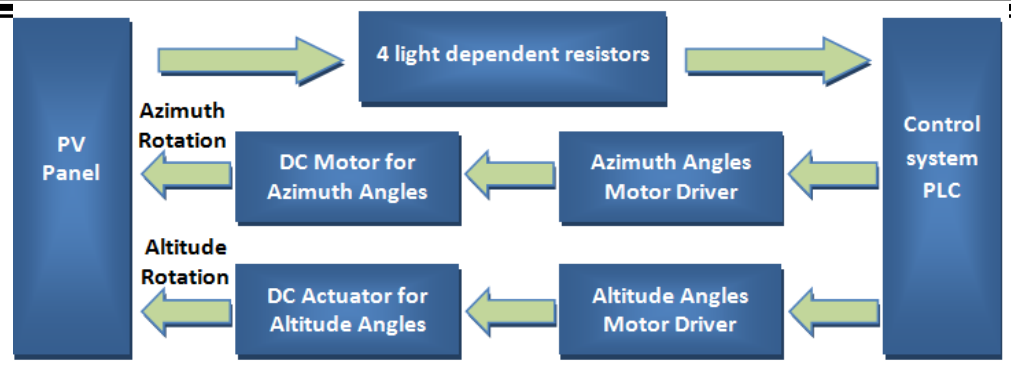

Fig. (1): System block diagram

Solar Tracking System is used to orienting a solar module to the sun; it needs a great amount of accuracy to guarantee that the sunlight is directed exactly to the powered device [1]. Exact tracking of the sun will be done through systems with single or multi axis tracking. The tracking system preferred rather than a fixed system because the power gain of solar system increases by 20 to $50 \%$ [1].

M. and, A.J. Calderón, A. Ramiro, J.F. and I. González are studied the exergy analysis of a testbed hybrid wind and solar generator with hydrogen support. The exergy balance analysis has been made by estimating the exergy losses and exergy efficiencies for the each component. Many advices proposed for improving the system by increasing its efficiency and reducing losses in it. The paper noticed poor advantages of today silicon modules from the high exergy contents in the solar radiation.

Mustafa and Dilshad Engin developed a control algorithm that increases effectiveness and reliability of the two-axis solar tracker, focusing on optimization of the each parts of the system. They studied and optimized the cost-effective of a sun tracker controller and their results were that the two-axis tracker has increased the energy collected by $40.7 \%$ while the improvement of the system cost increased by $21.1 \%$ [4].

Ercan 'IZG'I and Yunus Emre AKKAYA studied the exergoeconomic parameters of a solar photovoltaic. They analyzed the exergy and economic of a solar photovoltaic (PV) system using the (EXCEM) method in the two seasons spring and summer. They describes the solar affective in various weather conditions, and the effects of these factors on the economic yields. They measured the differences between the ratios of thermodynamic loss rate to capital cost values considering energy/exergy values in both months [5].
A. S. Joshi, I. Dincer and B. V. Reddy investigated in their study the performance of hybrid photovoltaic thermal air collector systems through energy and exergy efficiencies. The presented case study highlighted the importance of the modeling efficiencies and compares them with actual data. The obtained results were a higher energy efficiency $(33-45 \%)$, where the variation in the exergy efficiency was between 11 to $16 \%$ [6].

K. Sudhakar \& Tulika Srivastava studied the solar radiation's thermal and electrical energy. A thermodynamic evaluation done on the solar PV module to determine exergy losses and estimate the thermal, and electrical output values. Energy efficiency of the PV module was between $6 \%$ and $9 \%$, and exergy efficiency is ranging from $8 \%$ to $10 \%$. The study performed that exergy efficiency can be improved by evacuating heats from the PV modules, and the exergy losses will be increased by raising the PV module temperatures [7].

Sadyrbayevet. al.in 2013 [8] proposed a dualaxis sun tracking based on LM324N microcontroller with four photo resistors, which are mounted on the sides of the PV module. The analysis in this paper was done between a dualaxis and fixed tracking system. The obtained results from the paper were proved that the dualaxis tracking system produced $31.3 \%$ more power compared with fixed PV module.

In 2013, Ribeiroet. al.[9] presented a single axis tracking system to track the sun position. The results showed in a sunny day the increase of output power was more than $18 \%$.

In 2013,Arsalan[10] presented a single axis solar tracking system based on 8051 microcontroller. Two LDRs used for detecting the solar radiation difference. The system had automatic and manual tracking system operation.

In this paper, the energy and exergy analysis has been used to investigate the losses that affect the energetic and exergetic efficiencies. The 
portable PV module is used with the beam irradiance normal to the model. However, the effect of surface temperature, ambient temperature, solar irradiance and the output of the module has been investigated.

\section{Exergy and Energy Efficiencies}

Efficiency of photovoltaic solar modules is measured by the ability of a module to convert sunlight into usable energy for human consumption. Knowing the efficiency of a module is important in order to choose the correct modules for your photovoltaic system.

The module's efficiency is an important factor to choose the correct modules for your photovoltaic system. The photovoltaic solar module's ability in converting sunlight to usable energy represents the PV module's efficiency. It is calculated by the ratio of the power generated to the total, or global, solar irradiation.

Exergy is the maximum useful work that can be withdrawn when the system undergoes a reversible process from an initial state to a final state (commonly is environment state). Using exergy/exergy analysis techniques will helps to improve the researchers understanding, refining, and expecting the variations in solar PV behavior. It can be take benefits from the exergy analysis in designing and evaluating energy systems that reach an equilibrium state with its environment [11].

Performance is often evaluated in terms of efficiency, generally defined as the fraction of desired output over required input [12]:

$$
\text { Efficiency }=\frac{\text { Desired output }}{\text { Required input }}
$$

The PV module efficiencies are consists of: (1) energy efficiency, (2) exergy efficiency, and (3) power conversion efficiency. Energy efficiencies based on the first law of thermodynamics $(\eta 1)$, Dincer and Rosen estimated it [13] as:

$$
\eta_{1}=\frac{\text { Energy products }}{\text { Total energy Input }}
$$

Energy efficiencies are useful for bookkeeping of energy flows, but provide no information regarding the degradation of energy during a process. For this purpose efficiencies based on the second law of thermodynamics must be formulated in order to account for the consumption of exergy, the degradation of energy quality.

Exergy analysis has been shown to be a powerful tool in identifying energy quality losses in industrial thermodynamic processes. Exergy efficiencies (second law efficiencies) are a measure of how close to the ideal, reversible process a real process operates [13].

The photovoltaic efficiency evaluated by using the exergetic efficiency equation, it can be represents as the ratio of exergy useful (electrical exergy rate and thermal rate) on exergy of the solar radiation rate [14]:

$$
\eta_{\text {ex }}=\frac{\dot{E} x}{\dot{E} x_{\text {solar }}}
$$

Where, the input exergy or the solar radiations exergy is given by [14]:

$$
\dot{E} x_{\text {solar }}=\left(1-\frac{T_{a m b}}{T_{\text {sun }}}\right) I_{S} A
$$

And the exergy output of the solar PV module can be estimated as follows [14]:

$$
E x_{\text {out }}=E x_{\text {elec }}+E x_{\text {therm }}+E x_{d}+I^{\prime}
$$

Where the Irreversibility can be represent as [14]:

$$
I^{\prime}=\sum \dot{E} \mathrm{x}=E x_{d, \text { elect }}+E x_{d, \text { therm }}
$$

The Irreversibility includes all external and internal losses. The external losses are $E x_{d, \text { therm. }}$ or numerically is equal to $\dot{E} \mathrm{x}_{d, \text { therm }}$ for the PV system, where the internal losses are electrical exergy destruction $E x_{d, \text { elect }}$. The tracking system made the module against solar commonly, and for the calculation of electrical exergy $E x_{\text {elect }}$, it has been assumed that exergy content received by photovoltaic surface is fully utilized to generate maximum electrical exergy $\left(\mathrm{V}_{\mathrm{oc}} \mathrm{I}_{\mathrm{sc}}\right)$ [15].

$$
\dot{E} x_{\text {elec }}=\text { Ex elec }-I^{\prime}=\mathrm{V}_{\mathrm{oc}} \mathrm{I}_{\mathrm{sc}}-\left(\mathrm{V}_{\mathrm{oc}} \mathrm{I}_{\mathrm{sc}}-\mathrm{V}_{\mathrm{m}} \mathrm{I}_{\mathrm{m}}\right)
$$

Where, $V_{o c} I_{s c b}$ represents the electrical energy and $\left(\mathrm{V}_{\mathrm{oc}} \mathrm{I}_{\mathrm{sc}}-\mathrm{V}_{\mathrm{m}} \mathrm{I}_{\mathrm{m}}\right)$ represents the electrical exergy destruction.

Therefore the electrical exergy can be found as below [15]:

$\dot{E} x_{\text {elec }}=V_{m} I_{m}$.

The heat loss from the photovoltaic surface to the surrounding represents the thermal exergy of the system $\dot{E} x_{\text {therm }}$, it can defined as below [16]:

$$
\dot{E} x=\left(1-\frac{T_{a m b}}{T_{\text {cell }}}\right) Q
$$

The amount of convection heat transfer estimates by [16]:

$$
Q=\left[h_{c a} A\left(T_{\text {cell }}-T_{a m b}\right)\right]
$$

And convective (irradiative) heat transfer coefficient is equal to [16]:

$$
h_{c a}=5.7+3.8 v
$$


The upper equations can be summarized and collect as [17]:

$\dot{E} x_{P V}=V_{m} I_{m}-\left(1-\frac{T_{a m b}}{T_{c e l l}}\right)\left[h_{c a} A\left(T_{c e l l}-T_{a m b}\right)\right]$

Where the exergy loss is equal to [17] $\dot{E} x_{\text {loss }}=$ $\dot{E} x_{\text {solar }}-\dot{E} x_{P V}$

The Solar cell power conversion efficiency $\eta_{p c e}$ can by represented as a function of output power of the solar photo voltage module and the solar Intensity $I_{s}$, it can be estimate as follows [18]:

$$
\eta_{\text {pce }}=\frac{V_{m} I_{m}}{I_{s}}
$$

\section{Experimental Work}

Quantity of four light dependant resistorsLDRs was used to detect the light difference between the different directions (east, west, north, and west), they used in voltage divider circuit to detect the light, and are mounted on the solar tracking system frame as they are shown in figure 2. The analogue input voltage for PLC cards is varied between 0 and 10 Volts. A voltage divider output of less than 10V DC was achieved by using $12 \mathrm{~V}$ DC power supply.

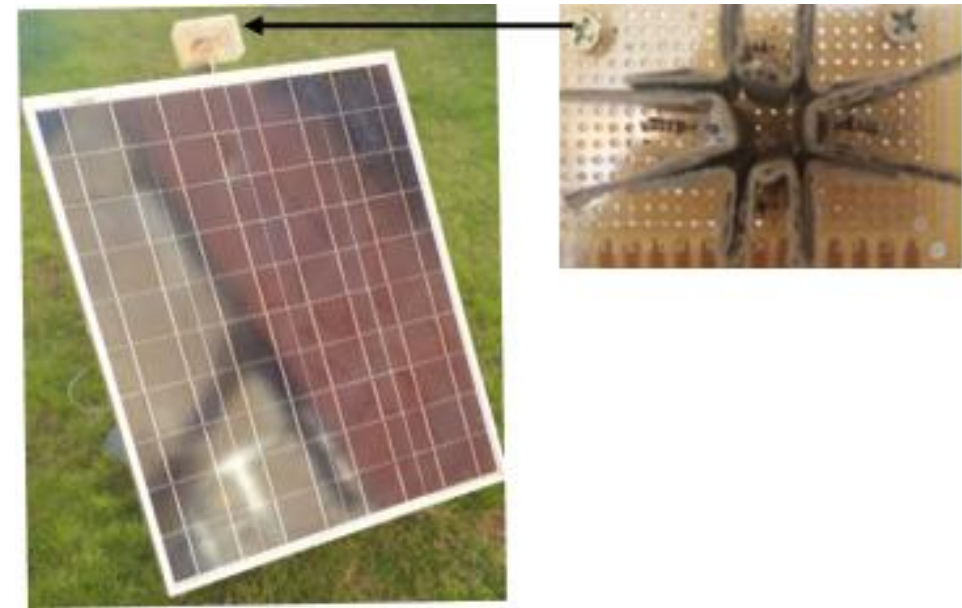

Fig.( 2): LDR's positions on the system

A mechanical frame (shown in figure 3) used for dual axis solar tracking system using PLC. It is consists of two parts, the upper part is to rotate the photovoltaic module to follow altitude angle of the sun between $0^{\circ}$ to $90^{\circ}$ by using a 24 inches, 36V $\mathrm{DC}$ actuator fed with $12 \mathrm{~V}$ DC to slow down its rotation speed to make rotations softer. The lower part rotates the photovoltaic module toward east and west to follow the sun's azimuth angle for 360 degrees using a $12 \mathrm{~V}$ high torque DC motor is used to rotate the module toward east and west to follow the sun's azimuth angle. The rotation speed of $12 \mathrm{~V} \mathrm{DC}$ motor is high and cannot be controlled by the control system; for that its speed decreased. Decrease of the DC motor speed done by applying lower terminal voltage $(3 \mathrm{~V}$ DC) and using two driven gears with (9/106) teeth ratio. Three bearings were used to smooth the rotation of the frame.

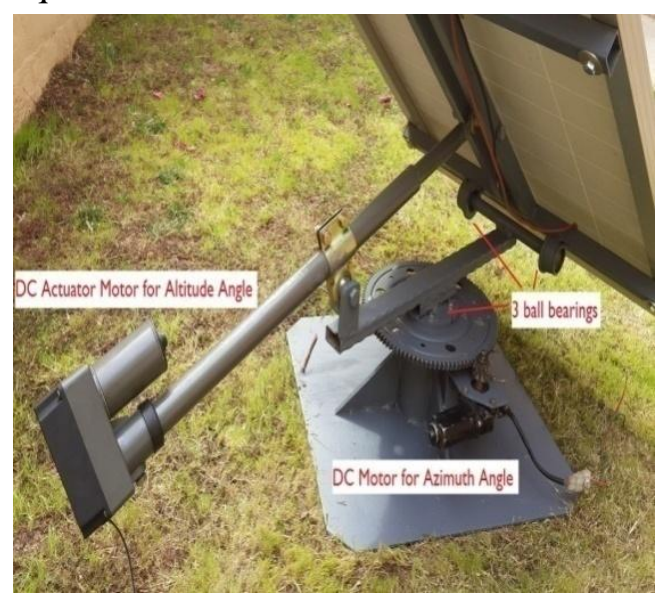

Fig. (3): Mechanical structure 
An accurate control system (Siemens S7-1214 DC/DC/DC PLC based control system) had been used to control the rotation of dual axis solar tracking system depends on the LDR sensors input. Figure 4, shows the prototype work of the control system.

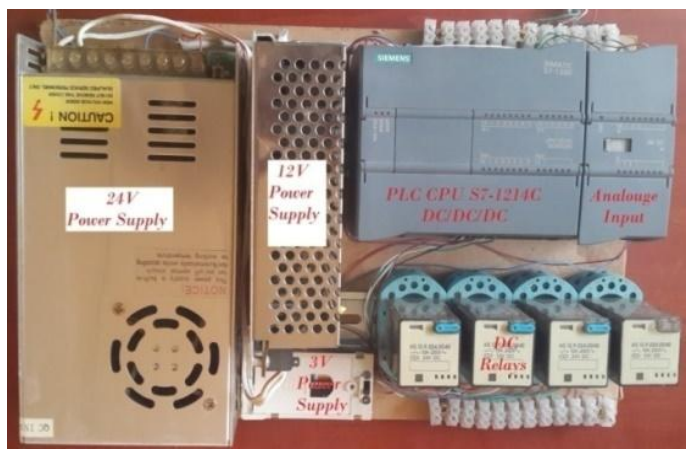

Fig. (4): PLC based control system

The specification of the PV module that has been used is:

Polycrystalline module

From RAGGIE power company

Dimension of module (mm): $835 \times 663 \times 35$

$\mathrm{V}_{\text {open }}=19.3$ volt

$I_{\text {short circuit }}=3.33 \mathrm{Amp}$.

$\mathrm{V}_{\text {max.power point }}=17$ volt $\quad$ standard condition

$\mathrm{I}_{\text {max. power point }}=2.96 \mathrm{Amp}$. standard condition

Load : $5 \Omega$

Area of Collector: $0.835 * 0.663=0.55 \mathrm{~m}^{2}$

\section{RESULT AND DISCUSSION}

The experimental study of the photovoltaic Module was performed from 9:00 am to 3:30 pm at the University of Salahaddin, Department of Mechanics, Erbil, Kurdistan Iraq, which is located at $36^{\circ} 14^{\prime \prime} \mathrm{N}, 44^{\circ} 01^{\prime} \mathrm{E}$. The test has been carried out on 5th of January 2017. The tabulated data (shown in table 1) has been calculated for clear sky day in the January. The measured data in the table 1 includes maximum power point current, maximum power point voltage, ambient temperature, PV module temperature, and the solar irradiance.

Table (1): The Obtained Data from the Experiment

\begin{tabular}{cccccc}
\hline Time & $\mathbf{V}_{\mathbf{m p} .}$ & $\mathbf{I}_{\mathbf{m p}}$ & $\mathbf{T}_{\text {amb. } \mathbf{K}}$ & $\mathbf{T}_{\text {Module } \mathbf{K}}$ & $\mathbf{S}_{\text {Beam W }}$ \\
\hline $09: 00$ & 11.25 & 2.25 & 281.15 & 295.15 & 832 \\
\hline $09: 30$ & 11.42 & 2.28 & 281.35 & 298.45 & 883 \\
\hline $10: 00$ & 11.62 & 2.32 & 284.05 & 299.75 & 961 \\
\hline $10: 30$ & 11.74 & 2.35 & 287.45 & 300.15 & 977 \\
\hline $11: 00$ & 11.76 & 2.35 & 288.45 & 300.45 & 1002 \\
\hline $11: 30$ & 11.74 & 2.35 & 289.05 & 300.55 & 950 \\
\hline $12: 00$ & 11.72 & 2.34 & 291.35 & 301.75 & 890 \\
\hline $12: 30$ & 11.70 & 2.34 & 291.55 & 304.25 & 980 \\
\hline $13: 00$ & 11.63 & 2.33 & 292.15 & 303.35 & 962 \\
\hline $13: 30$ & 11.60 & 2.32 & 291.95 & 300.65 & 945 \\
\hline $14: 00$ & 11.54 & 2.31 & 291.35 & 299.55 & 941 \\
\hline $14: 30$ & 11.00 & 2.20 & 290.85 & 297.35 & 885 \\
\hline $15: 00$ & 10.77 & 2.15 & 290.15 & 296.95 & 801 \\
\hline $15: 30$ & 10.33 & 2.07 & 288.45 & 295.35 & 714 \\
\hline
\end{tabular}


Figure 5 shows the relationship between energy and exergy outputs of the system with the variation of the surface temperature of the PV module. It is obvious that the energy output to the solar system increases till the temperature of the surface, $27^{\circ} \mathrm{C}$, is slightly above the standard surface temperature of the module and then starts to decrease due to the fact that the rise in surface temperature of the solar module the energy output decreases and reflects to decrease the efficiency of the system. The exergy output is less than that of the energy output and the reason is most of the energy output degraded within the module due to irreversiblitites of the components.

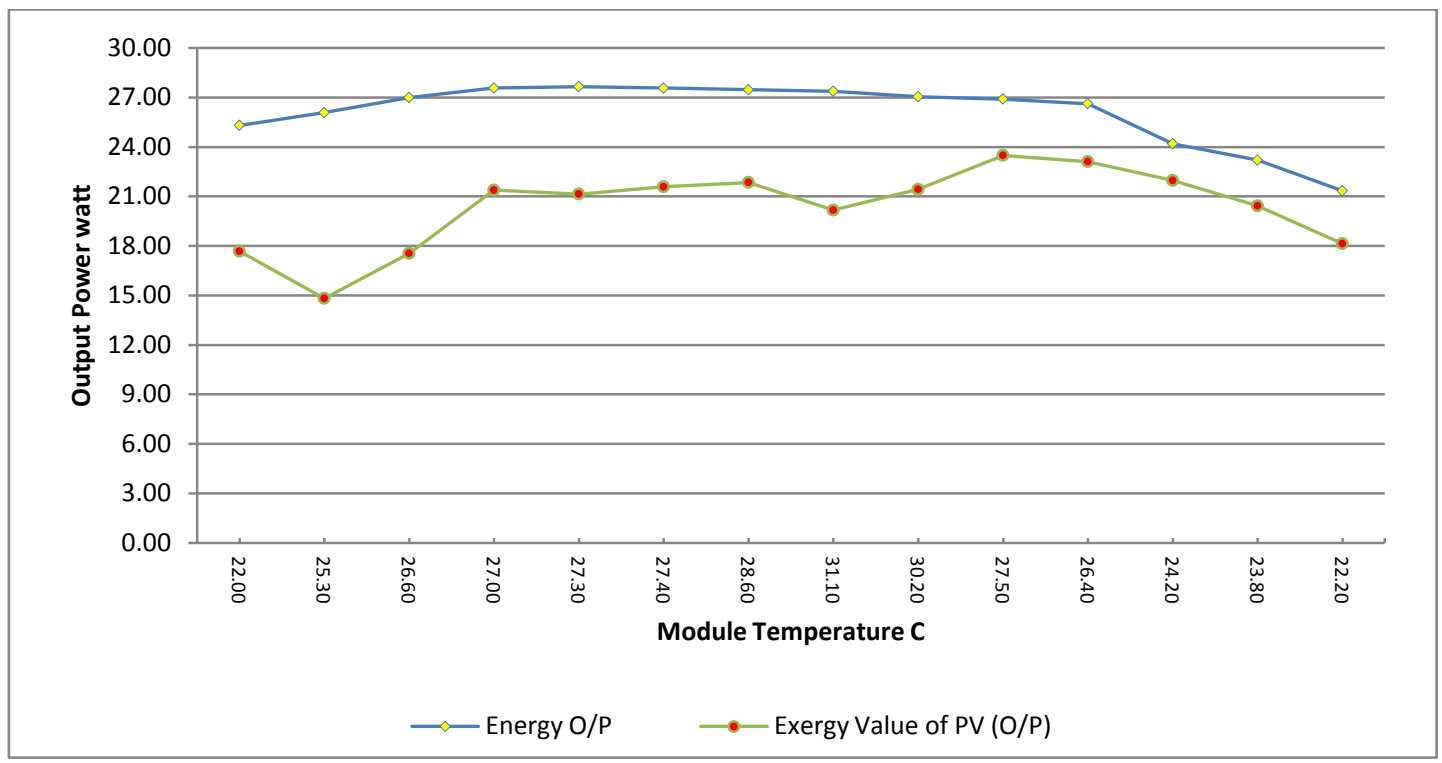

Fig. (5): Variation of surface temperature of the PV module vs. the energy output and exergy output of the system Figure 6 explains variations in efficiencies with respect to the surface temperature of the PV module. It is observed that the energy efficiency is (2-2.5) \% higher than the exergy efficiency of the module. The difference shows that some of the exergy entering the system is wasted in exergy destruction, therefore the exergy efficiency less than the energy efficiency.

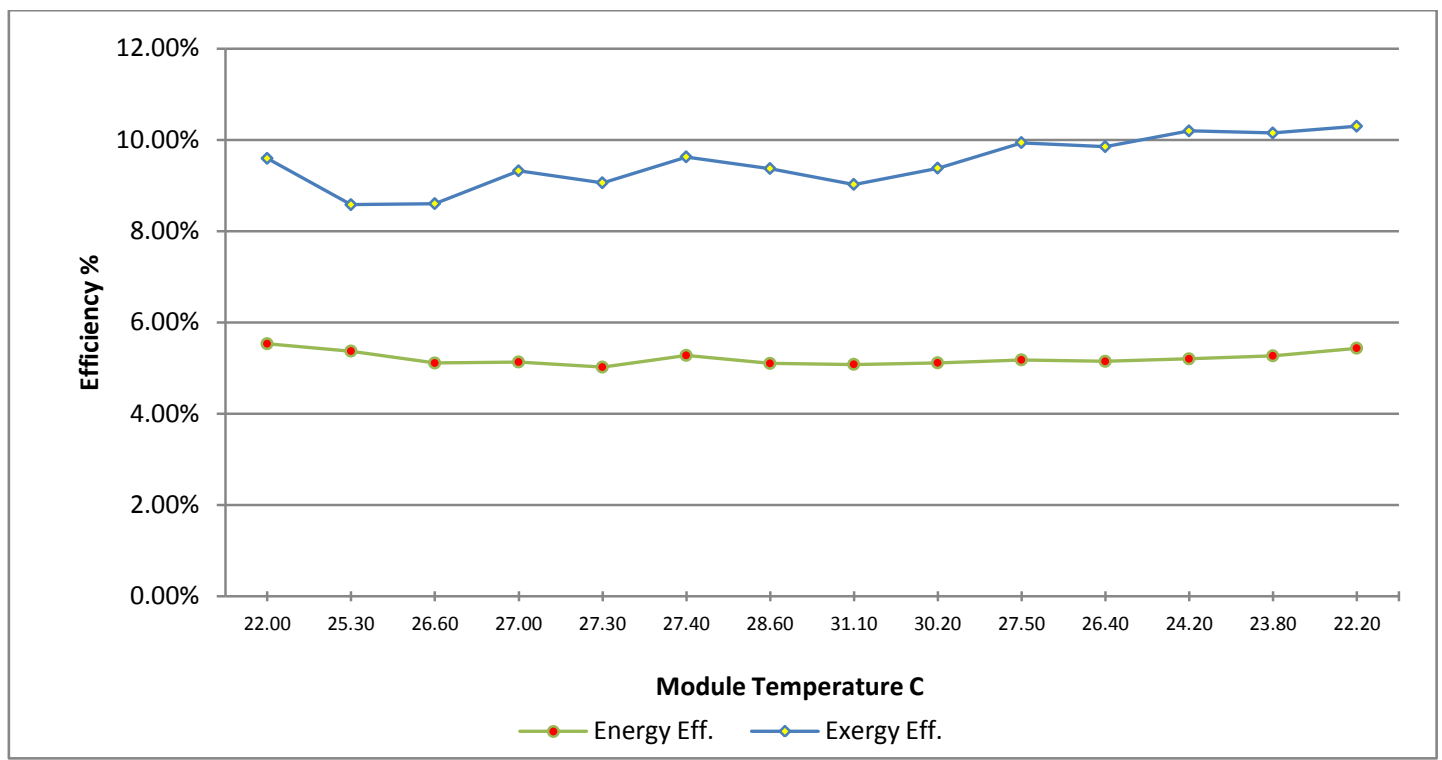

Fig. (6): The variation of surface temperatures of the module vs. the energy and exergy efficiency of the system. Figure 7 and figure 8 show the effect of solar irradiance on the amount of energy and exergy losses and on the value of the power outputs in the form of energy and exergy values during the interaction, respectively. The figure 7 shows how much value of the solar irradiance is destroyed and changed to heat within the system. The value of the 
energy loss is high when you compared to the exergy value because of some of solar irradiance is reflected and diffuses before entering to the module. Figure 8 compares the energy and exergy outputs with the variation of the value of the solar intensity of the sun. The higher the value of the energy input the lower the value of the exergy output due to the exergy destruction through the structure of the module. The output value of the module can be increased while the module is restructured and redesigned for the Kurdistan environment.

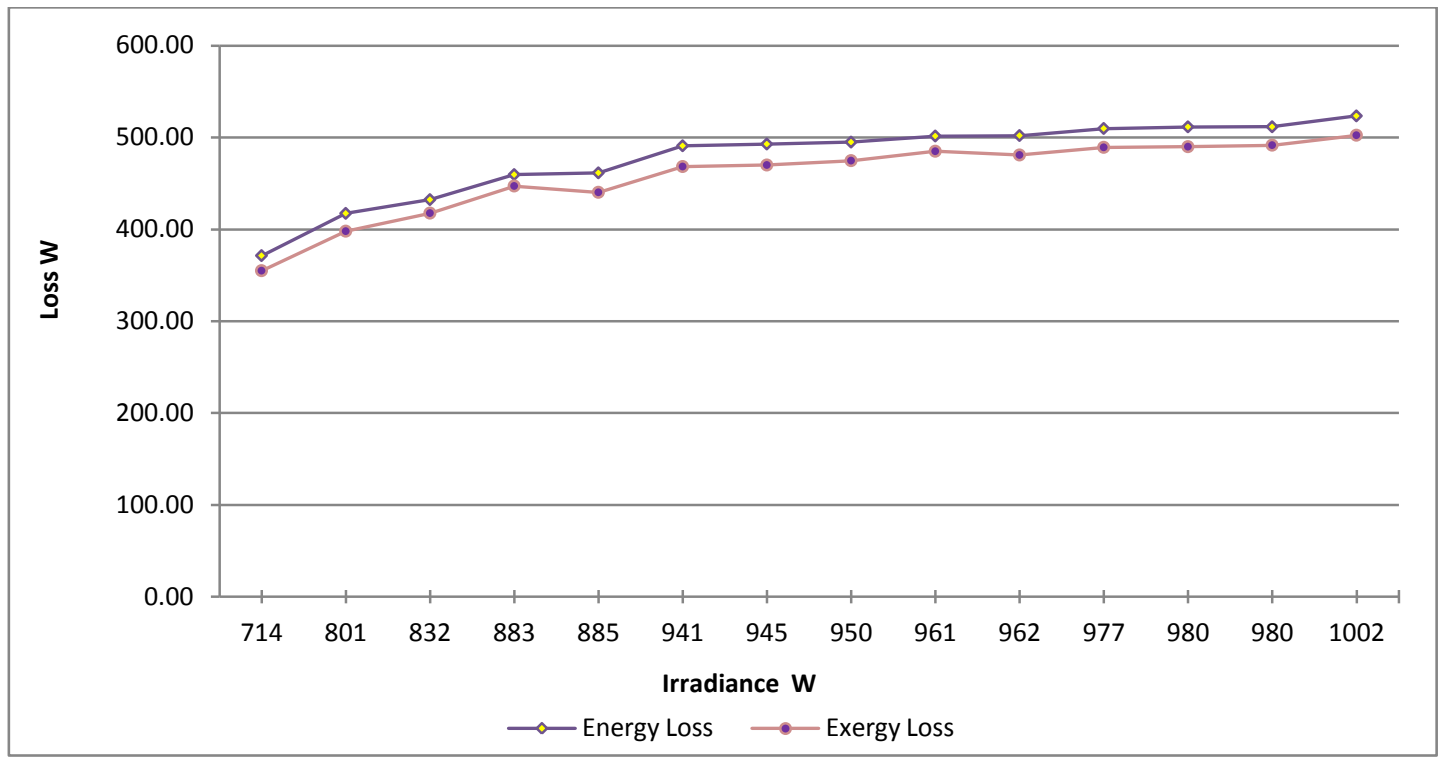

Fig. (7): The energy and exergy losses of the module vs. the solar intensity of the sun

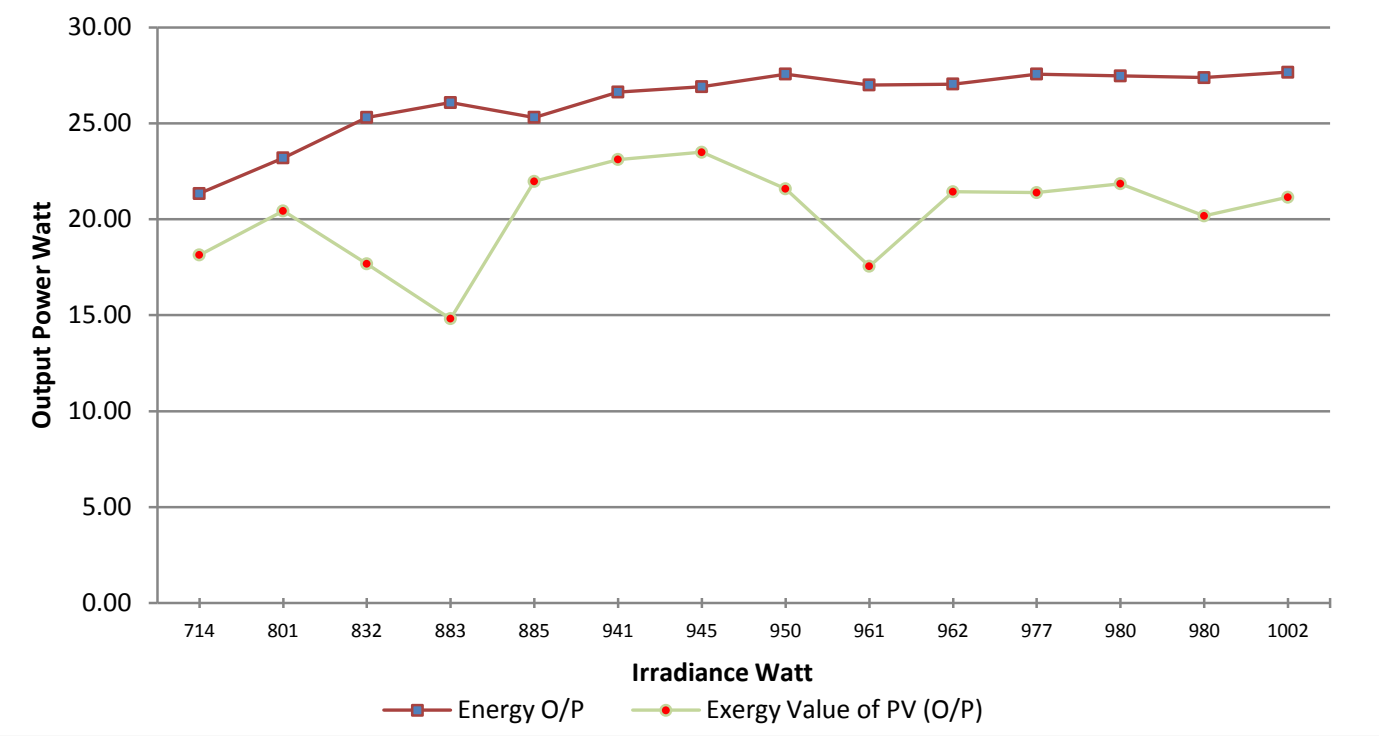

Fig. (8): The energy and exergy outputs of the module vs. the solar intensity of the sun Figure 9 shows the hourly variation of energy and exergy efficiencies with solar irradiance. The figure presents that most of the solar irradiance value is dissipated and not entered to the module. However, this dissipation of energy results in decreasing the value of the energy and exergy input to the system. It is clear that the energy input is greater than the exergy input because of waste of energy due to friction and heat losses that happened within the solar module. The shape of the energy and exergy curves follow that of the irradiance, and the greater the value of the irradiance, the greater the difference between them. 


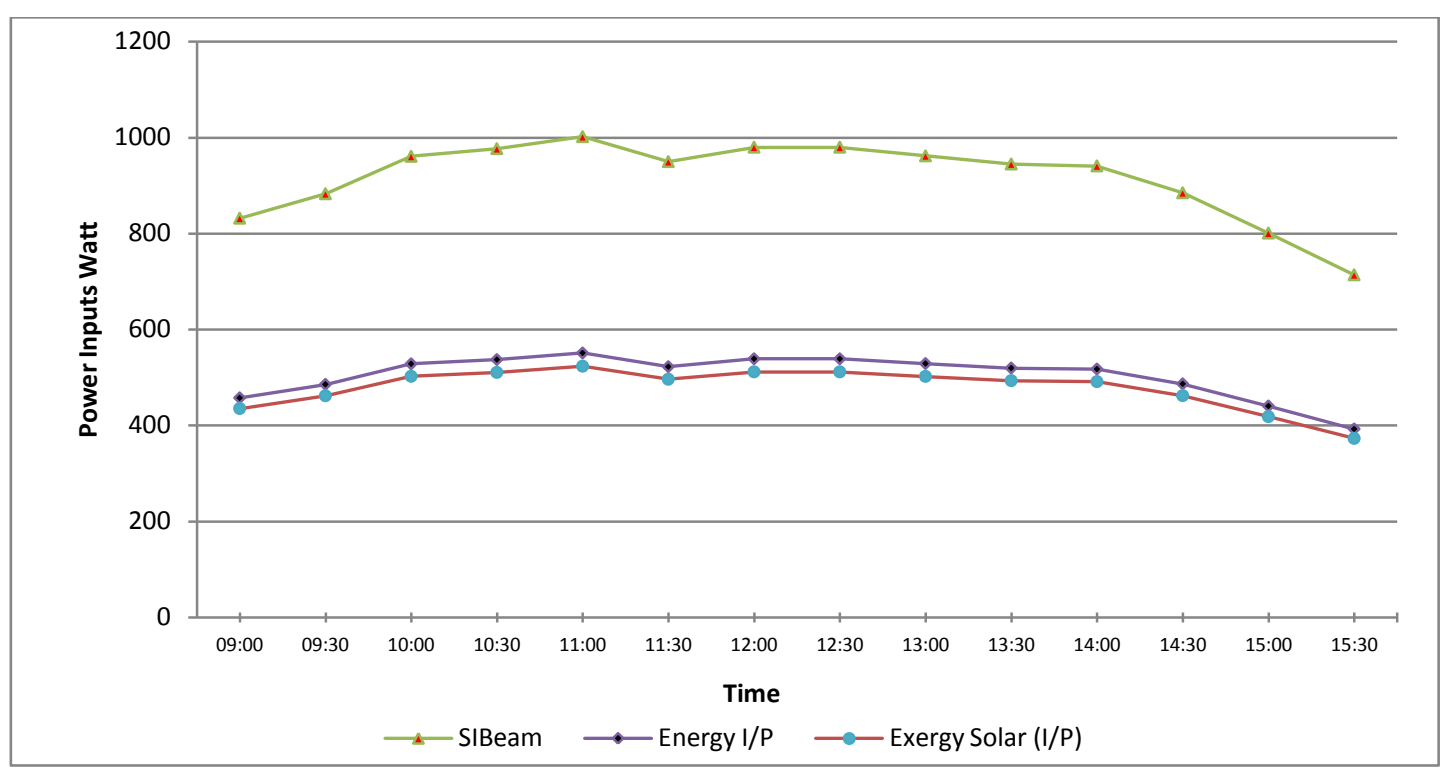

Fig. (9): Hourly variation of energy and exergy efficiencies with solar irradiance.

The hourly energy and exergy losses have been shown in figure 10. The increase in the value of the energy and exergy losses from the morning to about the noon time is because of increasing of the surface temperature of the solar module. Due to the irreversiblitites of the PV module conversion process and the wind speed next to the surface of the module the curves of energy loss higher than the exergy loss.

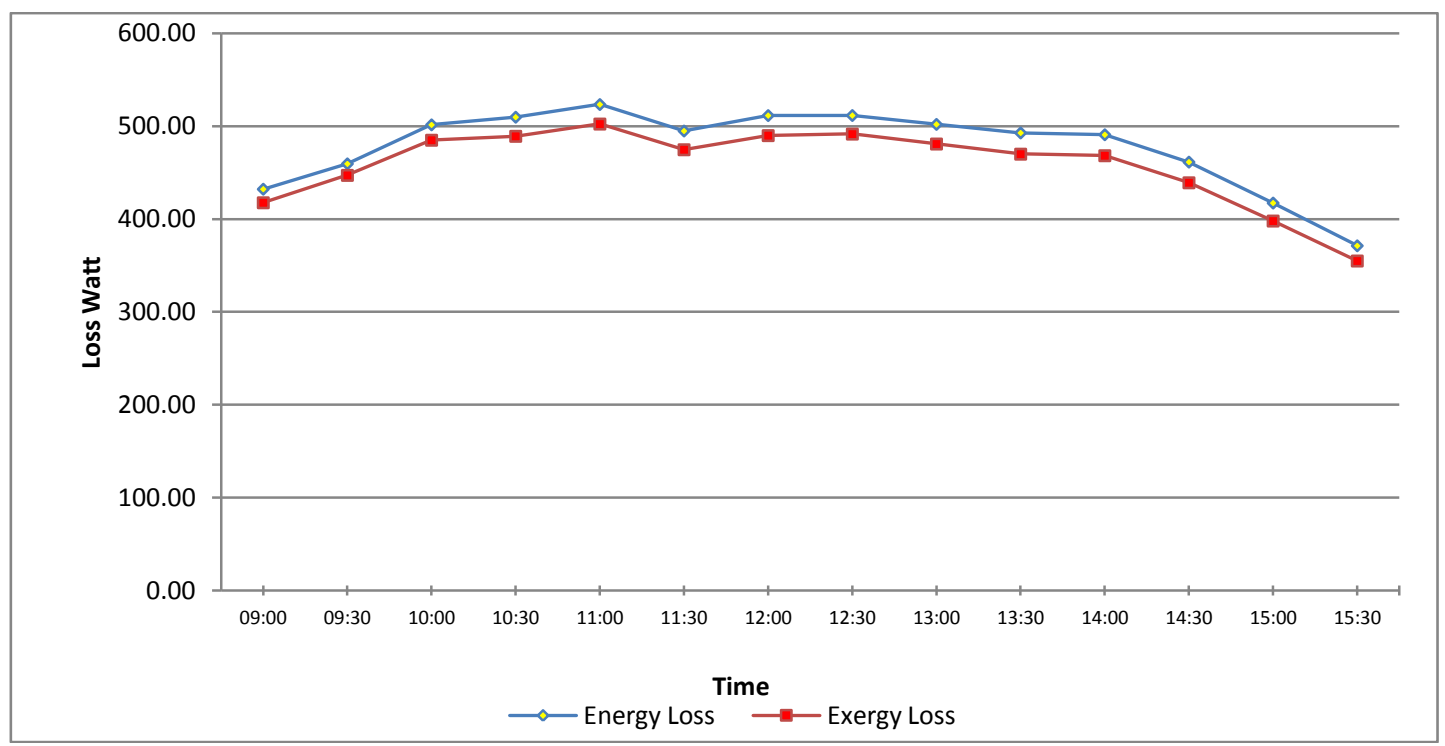

Fig. (10): Hourly variation of energy and exergy losses of the solar module.

The variation of energy and exergy efficiencies with the time is plotted in figure 11, where it is obvious that the energy efficiency of the system has higher values than the exergy efficiency. The difference between the energy and exergy analysis is high as it is expected the reason is the former is based on the maximum power point current and voltage and it is obvious that there is a thermal potential on the surface of the PV module, however, the exergy analysis is based on the actual voltage and current and the thermal potential does not included and comes up in the form of heat loss. In summery the proposed PV modules are considered as a major candidate for gaining energy from the sun, due to the fact that they can convert sunlight directly to electricity with moderate conversion efficiency. They can provide nearly continual electricity at low operating and maintenance costs, and are globally benign and sustainable. 


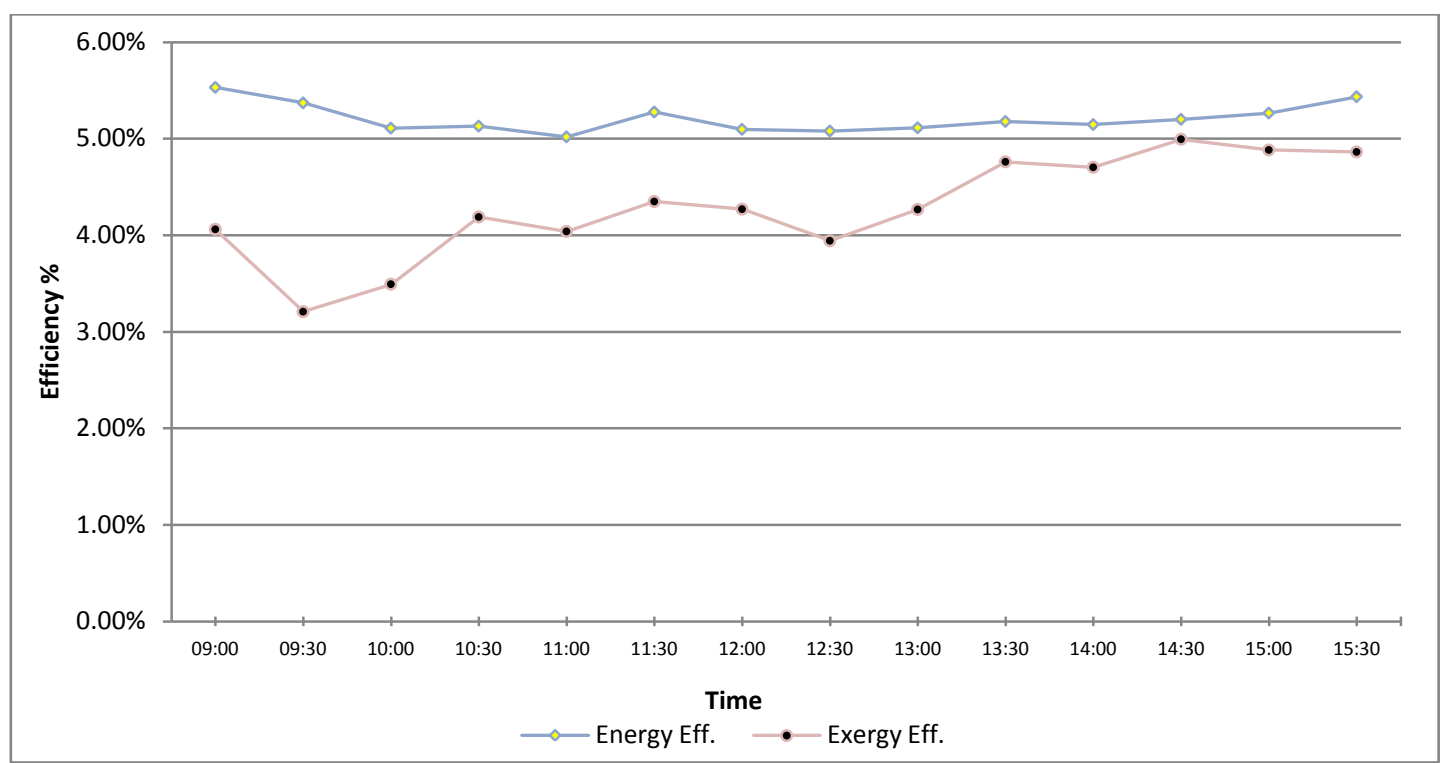

Fig. (11): Hourly variation of energy and exergy efficiencies of a PV system.

The two types of solar irradiance beam and diffusive radiations have been measured during the experimental test as shown in figure 12. In this paper, the beam intensity of the solar next to the surface of the solar module has been used. However, the diffusive solar irradiance measured and graphically compared to the beam intensity just to see that how much the diffidence is. The diffusive radiation has not used in this work because of using tracking solar PV module, which is always the sun rays are perpendicular on the PV module.

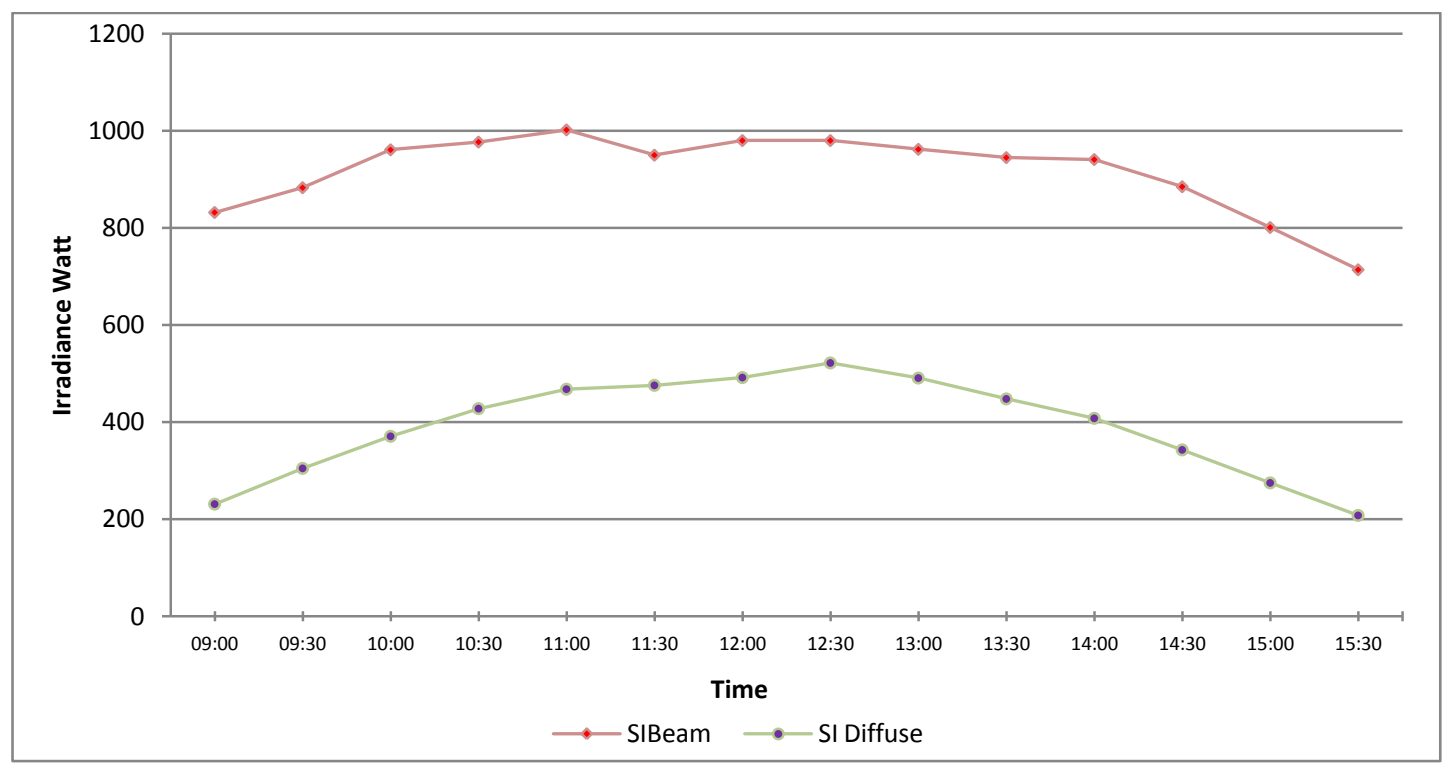

Fig. (12): The hourly variations of beam and diffusive solar irradiances.

\section{CONCLUSIONS}

After collecting and analysing of the practical results the following points could be concluded:

1. It is obvious that the energy output to the solar system increases till the temperature of the surface reaches slightly above the standard surface temperature of the module and then starts to decrease due to the fact that the rise in surface temperature of the solar module the energy output decreases and reflects to decrease the efficiency of the system. The exergy output is less than that of the energy output and the reason is most of the energy output degraded within the module due to irreversiblitites (frictions) of the components. 
2. It is observed that the energy efficiency is (22.5) \% higher than the exergy efficiency of the module. The difference shows that some of the exergy entering the system is wasted in exergy destruction.

3. The value of the energy loss is high when you compared to the exergy value because of some of solar irradiance is reflected and diffuses before entering to the module. The higher the value of the energy input the lower the value of the exergy output due to the exergy destruction through the structure of the module.

4. The results presents that most of the solar irradiance value is dissipated and not entered to the module. However, this dissipation of energy results in decreasing the value of the energy and exergy input to the system. The increase in the value of the energy and exergy losses from the morning to about the noon time is because of increasing of the surface temperature of the solar module.

5. The energy efficiency of the system has higher values than the exergy efficiency. The difference between the energy and exergy analysis is high as it is expected the reason is the former is based on the maximum power point current and voltage and it is obvious that there is a thermal potential on the surface of the PV module, however, the exergy analysis is based on the actual voltage and current and the thermal potential does not included and comes up in the form of heat loss.

\section{REFERENCES}

1. Tidell, J.W. and Weir, A.D. (1986) Renewable energy resources. London: E \& FN Spon.

2. Mostefa,G. (2001) 'Design of PLC based tracking system to maximize solar energy conversion', Eighth IEEE TEM, KFUPM Dhahran.

3. Calderón,M. , Calderón1,A.J. , Ramiro, A. , González, J.F. and González, I., (2011) 'Analysis of the performance of the photovoltaic array through the exergy efficiency', RE\&PQ J, Vol.1, No.9.

4. Engin, M. and Engin, D. (2015) 'Optimization controller for Mechatronic sun tracking system to improve performance', Advances in Mechanical Engineering, 5(0), pp. 146352146352

5. Ercan, I. and Yunus, E. A. (2013) 'Exergoeconomic analysis of a solar photovoltaic system in 'Istanbul, Turkey', Turkish Journal of Electrical Engineering \& Computer Sciences, No. 21: $350-359$.
6. Joshi, A.S., Dincer, I. and Reddy, B.V. (2010) 'Analysis of energy and exergy efficiencies for hybrid PV/T systems', International Journal of Low-Carbon Technologies, 6(1), pp. 64-69.

7. Sudhakar, K. and Srivastava, T. (2013) 'Energy and exergy analysis of $36 \mathrm{~W}$ solar photovoltaic module', International Journal of Ambient Energy, 35(1), pp. 51-57

8. Shyngys, A. S. ,Amangeldi, B. B., Seitzhan, O., and Zhanibek Z. K. (2013)'Design and Research of Dual-Axis Solar Tracking System in Condition of Town Almaty', Middle-East Journal of Scientific Research Volume 17, Issue 12, pp. 1747-1751.

9. G. A. G. Ribeiro1, A. da S. Antonio, T. M. S. Moreira1, G. Martins and H. A. Pereira, "Development of a Sun Tracker", IEEE conference, Sao Paulo, 15-17 April 2013, pp 1 6,University Fed. deVicosa, Vicosa, Brazil.

10. J. Armendariz, C. Ortega-Estrada, F. Mar-Luna, and E. Cesaretti, "Dual-Axis Solar Tracking Controller Based on Fuzzy-Rules Emulated Networks and Astronomical Year book Records", Proceedings of the World Congress on Engineering 2013, Volume1, July 3 - 5, 2013, London, U.K.

11. Bjørnar Sandnes, Exergy Efficient Production, Storage and Distribution of Solar Energy, University of Oslo November 2003.

12. Cengel, A. Y., Boles, M. A. (2005), Thermodynamics, An energy Approach $\left(5^{\text {th }}\right.$ ed. $)$. New York: McGraw-Hill.

13. Dincer, I., and M. A. Rosen(2013) 'Exergy Energy, Environment And Sustainable Development' Elsevier Second edition

14. Pandey, A., Pant, P., Sastry, O., Kumar, A. and Tyagi, S. (2015) 'Energy and exergy performance evaluation of a typical solar photovoltaic module', Thermal Science, 19(suppl. 2), pp. 625-636.

15. Tiwari, G.N. and Tiwari, A.K. (2016) Handbook of solar energy: Theory, analysis and applications: 2016. Singapore, Singapore: Springer Verlag, Singapore.

16. A. Shukla, M.Khare, and K N Shukla,(2015) 'Experimental Exergetic Performance Evaluation of Solar PV Module' International Journal of Scientific and Research Publications, Volume 5, Issue 1.

17. Duran Sahin, A., Dincer, I. and Rosen, M.A. (2007) 'Thermodynamic analysis of solar photovoltaic cell systems', Solar Energy Materials and Solar Cells, 91(2-3), pp. 153-159.

18. Y.E. Akkaya, (2011), 'Exergoeconomic Analysis of Wind and Solar Energy Systems', M.Sc., Yildız Technical University, Istanbul, Turkey,. 


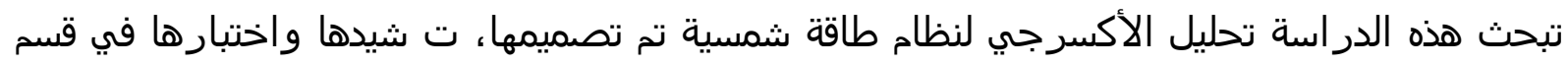

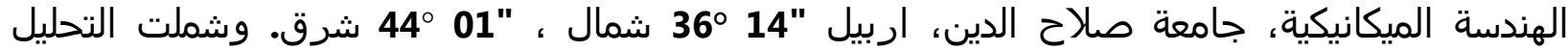

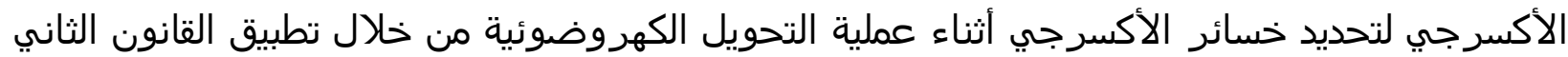

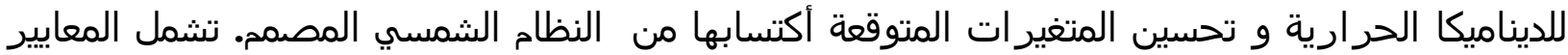

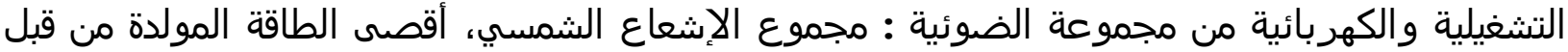

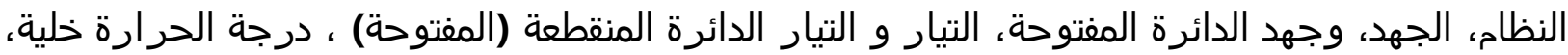

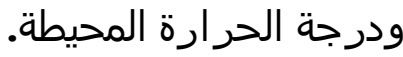

لتحديد موقع الشمس و لتوجيه المنظومة المدة الى أتجاه الشمس مباشرة، تح استعمال مقاومات تعمل على الضوء Light Dependent Resistors) LDRs) كموجه مدخلي لتحفيز النظام على نتيع الشمس و الدوران

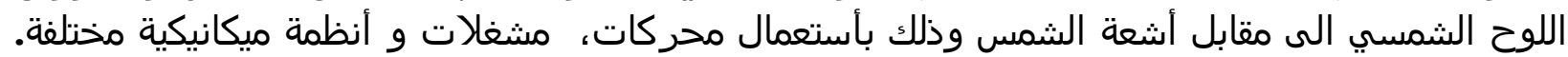

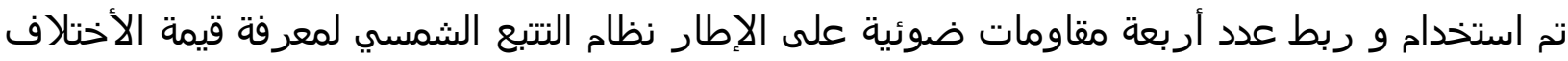

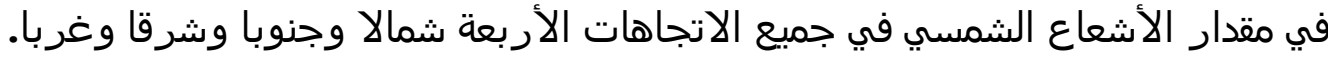

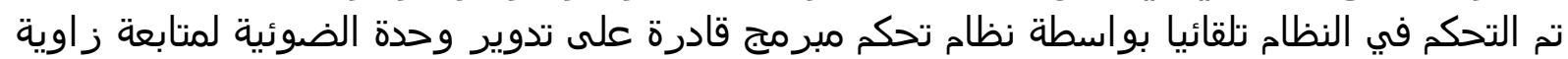
ارتفاع الشمس بين 0’ إلى 90" وذلك باستخدام مشغلات ميكانيكية بقياس "24 تعمل على محركات التيار

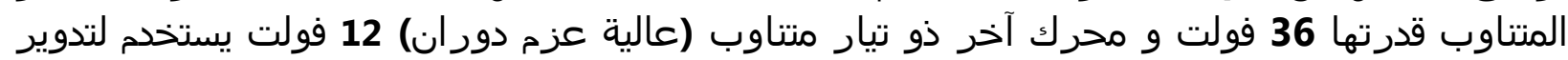

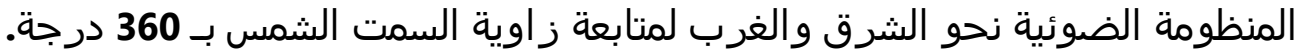

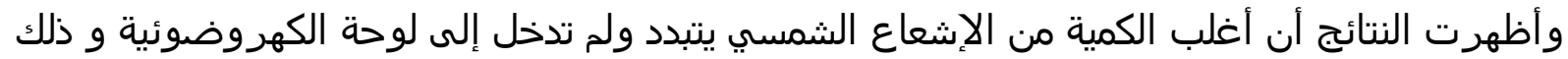

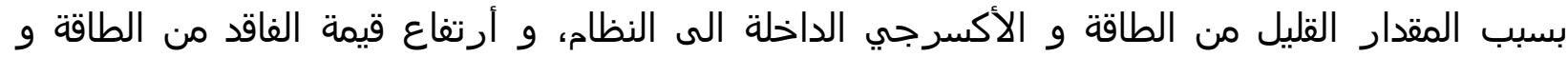

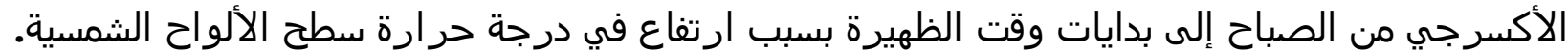

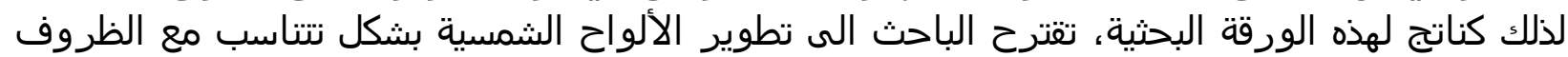

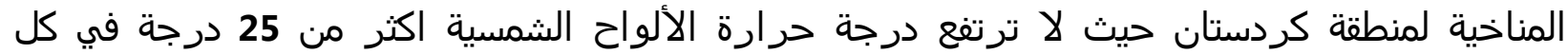

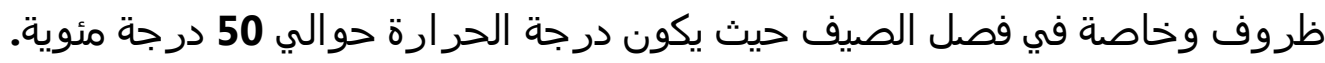

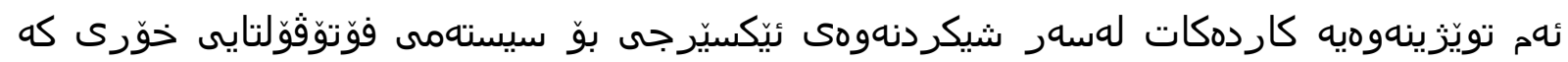

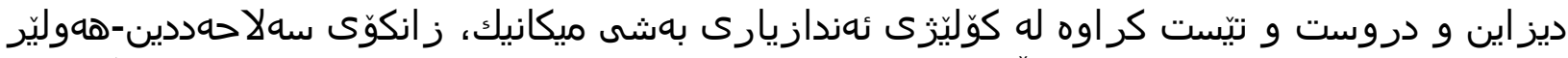

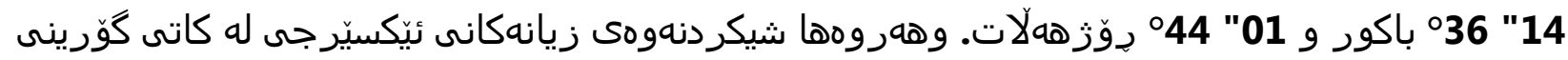

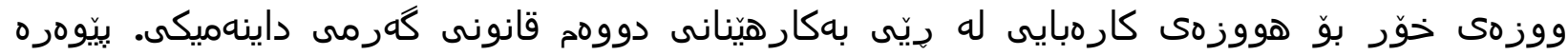

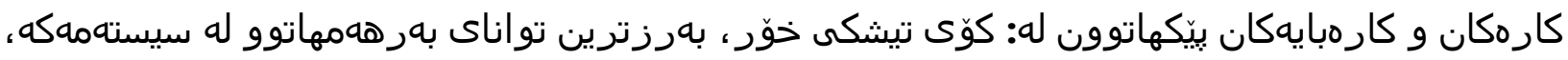




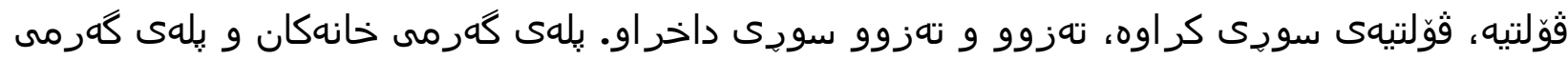
دموروبهر.

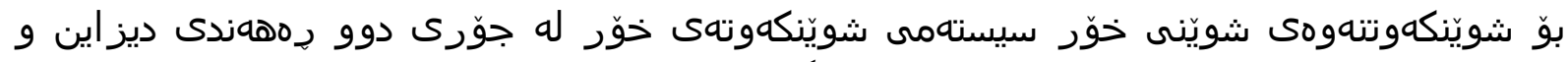

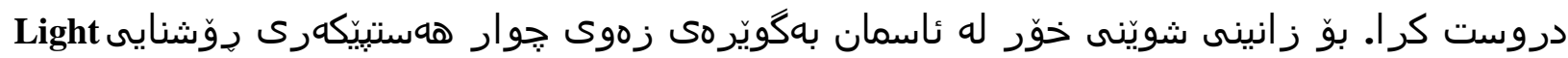

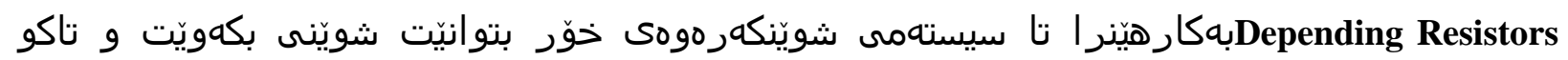

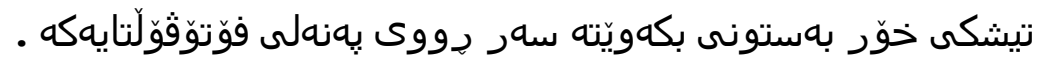

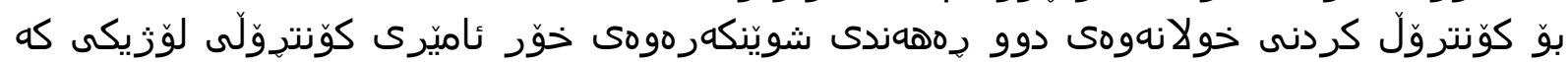

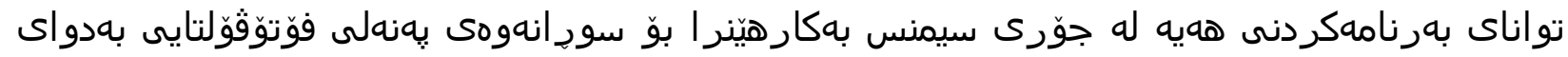

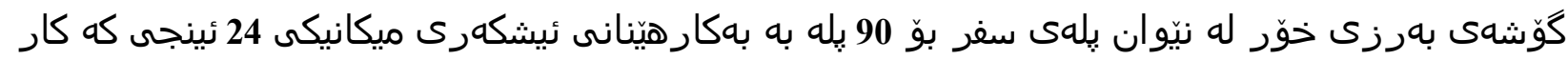

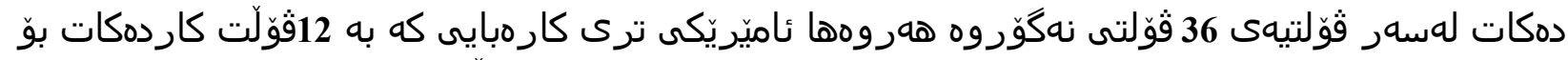

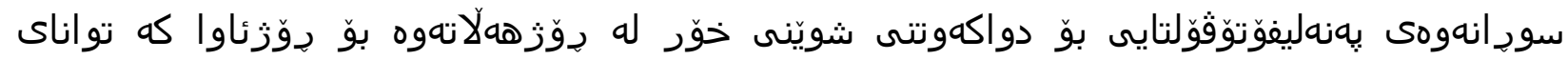

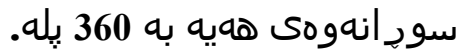

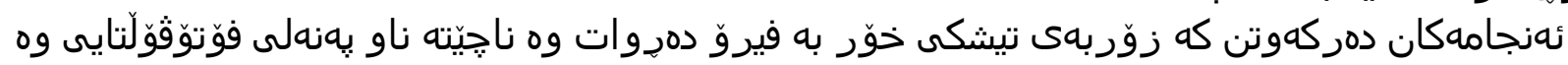

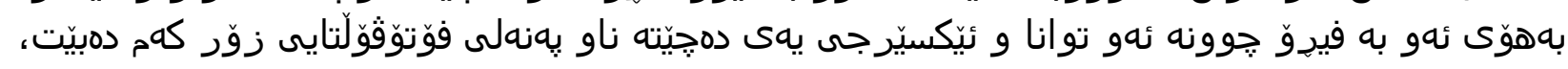

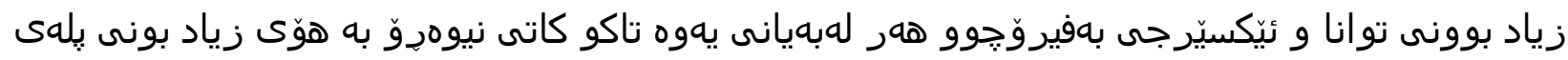

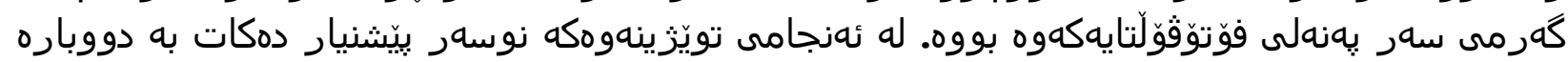

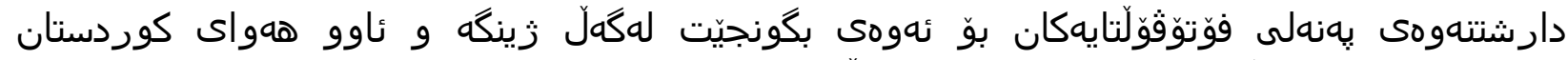

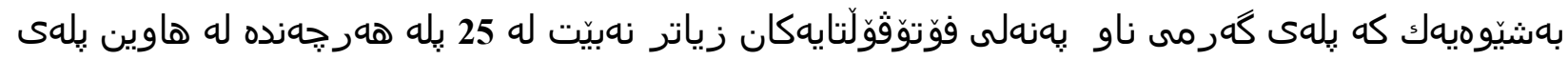

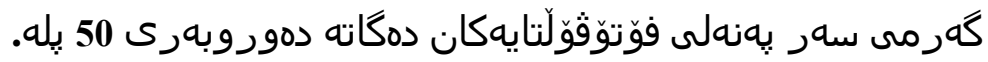


Journal of University of Duhok, Vol. 20,No.1(Pure and Eng. Sciences), Pp 381-393, 2017

elSSN: 2521-4861 \& pISSN: 1812-7568

https://doi.org/10.26682/sjuod.2017.20.1.35

Abbreviation

\begin{tabular}{lll}
\hline \hline \multicolumn{1}{c}{ Symbol } & & \multicolumn{1}{c}{ Unit / value } \\
\hline $\mathrm{V}_{\mathrm{mp}}$ & Maximum Power Point Voltage & Volt \\
$\mathrm{V}_{\text {open }}$ & Open Circuit Voltage & Volt=19.3 volt \\
$\mathrm{I}_{\mathrm{mp}}$ & Maximum Power Point Current & Amp. \\
$\mathrm{I}_{\text {short circuit }}$ & Short Circuit Current & Ampere $=3.33$ Amp. \\
$Q$ & Convection heat transfer & $\mathrm{W}$ \\
$h_{\text {ca }}$ & Convective heat transfer coefficient & $\mathrm{W} / \mathrm{m}^{2} . \mathrm{K}$ \\
$v$ & Wind Speed & $\mathrm{m} / \mathrm{s}$ \\
$\mathrm{T}_{\text {amb. }}$ & Ambient Temperature & $\mathrm{K}$ \\
$\mathrm{T}_{\text {Module }}$ & Module/ Module Temperature & $\mathrm{K}$ \\
$\mathrm{Sl}_{\text {Beam }}$ & Sun Intensity & $\mathrm{W}$ \\
$\mathrm{A}$ & Area of the PV Module & $\mathrm{m}{ }^{2}$ \\
$\eta_{\text {ex }}$ & Exergetic Efficiency & $\%$ \\
$\mathrm{Ex}_{\mathrm{d}}$ & Exergy Destruction & \\
$E x_{d, e l e c t}$ & electrical exergy destruction & \\
$E x_{d, \text { therm }}$ & Thermal exergy destruction & \\
$E x_{\text {ou }}$ & exergy output of the solar PV & \\
$\mathrm{I}$ & Irreversibility & \\
$\mathrm{PV}$ & Photovoltaic & \\
$\mathrm{T}$ & Time & $\mathrm{sec}$.
\end{tabular}

